\title{
SEMBLANZA DE Miguel SERVET, REFORMADOR Y DEFENSOR DE LA LIBERTAD DE CONCIENCIA*
}

\author{
José MARTÍNEZ DE PISÓN CAVERO \\ CATEdRÁtico de Filosofía del DERECHO \\ UNIVERSIDAD DE LA RIOJA
}

En la teoría de la argumentación práctica, Neil McCormick hace unos años distinguió entre el contexto de oportunidad y el contexto de justificación. En el caso de esta lección sobre la controvertida figura de Miguel Servet, la oportunidad viene dada por la reciente celebración del V Centenario de su nacimiento, un 29 de septiembre de I5II. Este tipo de efemérides son, en principio, una buena razón para rememorar y revivir hechos y personas relevantes de nuestro pasado. En cuanto a la justificación de fondo, lo que me interesa es presentar y convencer al auditorio de, más allá del conocimiento general o tópico de su personalidad y de sus aportaciones, la importancia histórica de Miguel Servet en la lucha y reconocimiento de uno de los pilares básicos de nuestra convivencia, como es, en suma, la tolerancia, la libertad de creencias, la libertad de conciencia.

Pocas personas, en ese momento histórico, sin ser conscientes de ello, han tenido tal relevancia. Sólo es equiparable en entereza y firmeza el católico Tomás Moro cuando se resistió a las veleidades político-religiosas de un Enrique VIII. Su actitud, la de ambos, pondrá en primera línea de atención la necesidad de la tolerancia y de la libertad de creencias, una libertad que, para sí reclamaban los reformadores, pero que, con el tiempo, ellos mismos violarán, como inteligentemente, en el caso de Servet, pondrá de manifiesto Sebastian Castellio y, tras él, las cabezas más brillantes de la cultura europea. Esto es, en suma, lo que pretendo contarles hoy, a la manera clásica, es decir, con la palabra.

En la actualidad, está suficientemente comprobado que Miguel Servet nació un 29 de septiembre de I5II, en Villlanueva de Sijena (Huesca). Murió un 27 de octubre de I553 en Ginebra, convertida entonces en una teocracia autoritaria gobernada por el reformador Juan

\footnotetext{
* Este texto corresponde a la exposición oral que hizo el autor en el acto de inauguración del curso 20I2/20I3 de la Universidad de La Rioja. Aunque la institución académica publicó un escrito más completo, el que aquí se presenta es diferente en parte y expone la figura de Miguel Servet, con los mismos mimbres, desde otra perspectiva. Se han suprimido, lógicamente, las referencias propias del acto en que se dictó la lección. No obstante, no quiero dejar de aprovechar la oportunidad de agradecer al Rector y a su equipo el que me hubiesen designado para el alto honor de dictar la primera lección del curso 2012/2013.
} 
Calvino. Como es sabido, Servet fue condenado a morir en la hoguera por hereje. Entretanto, su vida discurrió accidentadamente, la mayor parte en Francia y ocultando su identidad.

En la vida de Servet, al menos, cuatro personas fueron determinantes: fray Juan de Quintana, a quien su padre encomendó para dar los primeros pasos en su formación; Sinforiano Champier, que lo encaminó hacia la generalidad del saber, especialmente, en medicina y astrología; el arzobispo católico Pierre Palmier, quien daría cobijo al hereje durante doce años, los más confortables en la vida de Servet; y, finalmente, Juan Calvino.

En I525, el padre de Servet consigue que su hijo acompañe como paje y secretario a fray Juan de Quintana cuya influencia en Miguel fue considerable. Gracias a él, pudo conocer de primera mano las discusiones, las polémicas religiosas y los procedimientos judiciales que surgían en España. En particular, la potente corriente erasmista. Con Quintana, confesor real, conoció además España y, tras completar sus estudios jurídicos en la Universidad de Toulouse, asistió a la coronación del emperador en Bolonia, I530. Los fastos de la Iglesia en Roma acabaron por convencer al impetuoso Servet de la necesidad de la reforma de la religión católica en un proyecto cuyo objetivo era la «restitución» del cristianismo de los primeros siglos, es decir, la vuelto a los tiempos anteriores al Concilio de Nicea.

Los años siguientes, desde I530 a I532, Miguel Servet está en Basilea, Estrasburgo; debate y discute con reformadores de segunda fila, como con Juan Ecolampadio de quien pretendió ser discípulo y quien acabó rechazándolo. Además, escribe sus dos primeras obras Sobre los errores de la Trinidad y Dos diálogos sobre la Trinidad, que serán el origen de su principal escrito Restitución del Cristianismo.

Servet tenía entonces 2I años. Ya entonces fue perseguido por la Inquisición aragonesa y se le cerraron las puertas de las ciudades alemanas y de Suiza. Es entonces cuando decide ir a Francia, Lyon y París, y, para evitar males mayores, cambiar su identidad por la de Miguel de Villanueva, o Miguel de Villeneufve, nacido en Tudela.

En un ir y venir entre Lyon y París, Servet conoce a Sinforiano Champier, médico, erudito, filósofo neoplatónico, teólogo, abogado y astrónomo, todo lo que acabará siendo nuestro aragonés. Lo importante es señalar que dirigirá sus pasos hacia la medicina siendo uno de sus discípulos más destacados. En la Facultad de Medicina en París, Servet tendrá buenos maestros y será condiscípulo de uno de los anatomistas más famosos de la época, de Andrés Vesalio, quien escribiría De humani corporis fabrica. Más conocida por Fabrica, libro con el que muchos médicos aprendieron los rudimentos de la anatomía humana.

Fruto de este magisterio y de esta colaboración en las disecciones y análisis anatómicos, del conocimiento y de la crítica a Galeno, de su estudio de la medicina arábiga, surgirá la concepción servetiana de la circulación menor de la sangre que expondrá, de acuerdo a su concepción de la naturaleza y del ser humano, no en un libro de medicina, sino en su tratado de teología Restitución del Cristianismo. Esta ubicación no constituye un error, sino la manifestación de que Servet creía que el alma estaba residenciada en la sangre, especie de elán vital que, al oxigenarse en su paso del corazón a los pulmones, al mismo tiempo, purifica y vivifica nuestro espíritu.

De esta época, es también la pasión de Servet por la astrología, pero no cualquiera, sino la «astrología judiciaria» que, al cabo, le traería más de una complicación. La astrología judiciaria era considerada una seudo-ciencia, cercana al ocultismo y castigada como herejía. De acuerdo a la alineación de los astros era posible conocer y anticipar hechos sobre la conducta y sobre acontecimientos relevantes. De hecho, Servet vaticinó grandes catástrofes al anticipar un eclipse de Marte por la Luna para febrero de 1538, lo que, según su buen 
entender, suponía, una mayor excitación del corazón de los leones, es decir, de los príncipes, y que, de ello, se derivarían más guerras y los peores males.

La previsión se cumplió y Servet fue denunciado ante el decano de la Facultad de Medicina. Como el aragonés, era incapaz de callarse, insultó a la autoridad académica y el caso acabó en el Parlamento de París que, reunido el I8 de marzo de I538, dictó una sentencia leve que aún permitió a Servet volver a matricularse en la Facultad de Medicina. Sale bien parado de un proceso que ya podía haberle llevado a la hoguera, pues, en el colmo de la inconsciencia, aún se atrevió durante estos meses a escribir una Apologética Disceptio pro Astrologia.

Servet, con buen criterio, abandona París y busca un lugar más seguro para vivir. Durante los años siguientes, acabó medicina; no se sabe muy bien si en Lyon, Avignon o en Montpellier.

En I54I, el ya obispo Pierre Palmier, a quien conocía Servet precisamente de las conferencias sobre astrología, le propone el trabajo de médico de cámara en la ciudad de Viena del Delfinado. Serán los años más felices de su «atribulada existencia». Llevará una vida integrada en la comunidad ejerciendo de médico, pero, al mismo tiempo, va a ir elaborando y madurando su proyecto teológico, la restauración del cristianismo primigenio.

En Viena de Delfinado, Servet vivió sus años (ı2) más confortables y podía haber continuado así, una vez que se naturalizó francés y mantuvo su identidad oculta. Pero, como la cabra tira al monte, una vez instalado en la vida apacible y burguesa de esta ciudad, poco a poco, fue dando los pasos que le acabarían conduciendo a su triste final.

Servet y Calvino ya se conocían de los días en la Universidad de París donde estuvieron a punto de enfrentarse en una disputatio teológica a la que no acudió el aragonés. Ausencia que Calvino no perdonaría jamás, pues puso en peligro su vida.

Para 1546, Servet había ya escrito un primer manuscrito de su Restitución del Cristianismo e inicia una relación epistolar con Calvino que lo acabaría traicionándolo. A pesar de que uno y otro utilizaron una identidad falsa, Calvino no se engañó nunca sobre la verdadera persona que estaba detrás del nombre de Michel de Villeneufve. En esta correspondencia, Servet cometió un sinfín de errores y sirvió en bandeja una material que luego sería utilizado a su debido tiempo por su enemigo.

Todo este material serviría para condenar a Servet. Calvino hará entrega a los delatores de esta correspondencia para que, paradójicamente sea la católica Inquisición francesa la que primero persiga al aragonés. Podemos imaginar la sorpresa del arzobispo Palmier cuando tuvo conocimiento del pensamiento oculto de Servet y cuando fue consciente de que, durante años, había estado protegiendo a un hereje.

Calvino tenía claro cuál sería el resultado final de su duelo con Servet. En una carta del I3 de febrero de 1546 enviada a Guillermo Farel, Calvino ya aclaró sus intenciones: «Servet me escribió hace poco y adjuntó a su carta un gran volumen con sus delirios, anunciándome con trasónica fanfarronería que vería en él cosas admirables y hasta inauditas. Se ofrece a venir, si me agrada, pero no quiero darle mi palabra. Pues, si viene, por poco que valga mi autoridad, nunca dejaré que salga vivo».

Siete años más tarde tendría esta oportunidad. La publicación de la obra teológica de Servet puso en marcha todos los mecanismos represores del calvinismo para evitar que viera la luz y, al mismo tiempo, castigar a su autor. Tras las primeras denuncias en Viena 
del Delfinado y su huida de la ciudad, en la que también fue procesado y quemado en efigie, Servet, de forma sorprendente, aparece un I3 de agosto de I553 en Ginebra donde rápidamente es hecho prisionero $\mathrm{y}$, en un juicio rápido, condenado a morir en la hoguera el 27 de octubre en la colina conocida con el nombre de Champel o Campo del Verdugo.

La actitud vital y la posición intelectual de Miguel Servet merecen un sitio importante sitio-, en la historia por la lucha por la libertad de conciencia y, en definitiva, por los derechos individuales. Y este puesto, bien merecido, se debe a dos circunstancias no desdeñables. Por un lado, a su actitud vital ante el proceso iniciado por Calvino y sus secuaces. Por otro lado, por cuanto, en el fragor de la defensa de su pensamiento, de su teología y de su vida, esbozó unas primeras ideas sobre la libertad de conciencia que bien desarrolladas iniciaron y dieron lugar al proceso antes descrito de surgimiento de los derechos individuales desde la reivindicación de la tolerancia.

El proceso inquisitorial contra Servet, los debates, las réplicas y contrarréplicas, el trato vejatorio al que fue sometido en prisión, en fin, las diferentes circunstancias que rodearon su persecución, han sido ampliamente estudiados. En sus diferentes actos, en la crueldad y en el sufrimiento personal, Servet mostró una actitud vital ejemplar, quizá propia de su genética aragonesa, pero, en todo caso, un modelo de compromiso consigo mismo y con su pensamiento.

Tómese como ejemplo de esta actitud el relato de los últimos momentos, casi segundos, de vida de Servet en los que, pese a haber sido condenado, todavía podía salvar su vida con un postrer arrepentimiento. Como se ha descrito en más de una ocasión en una narración auténticamente de película, cuando se arrastraba hacia Champel, el Campo del Verdugo, incluso cuando se cuerpo empezaba a ser devorado por las llamas y el ministro calvinista de Ginebra, Guillermo Farel, le preguntaba: «¿Crees en Jesucristo, Hijo eterno de Dios?», aún Servet tenía fuerzas para responder: «iCreo en el Cristo verdadero, hijo de Dios, pero no eterno!». Frase con la que resume su teología, su ideario antitrinitario y también su sistema filosófico y su personalidad.

A lo largo del proceso, Servet mostró el mismo carácter y la misma persistencia por defender su pensamiento, contrarrestar ideas, discutir y debatir lealmente posiciones teológicas tan distintas como la suya y la de Calvino. Desde el iz de agosto, fecha en la que se produce la denuncia y detención del aragonés, hasta el 27 de octubre de I553, día en el que es quemado en la hoguera, se suceden diversos interrogatorios, acusaciones, cruce de escritos de disputa con Calvino y remisión de cartas de denuncia de su penosa situación. Fueron meses de angustia sin medios, sin asistencia jurídica, finalmente, enfermo y en una prisión en un estado lamentable, en los que muestra el mismo tesón y defensa de su doctrina pese a no ser escuchado ni por sus inquisidores, ni, por supuesto, por Calvino. Muy superior en conocimiento teológico, filológico e histórico y en dialéctica a sus acusadores, Servet siempre puso en un brete a cuantos le interrogaron. E, incluso, los investigadores señalan que fue también muy superior a Calvino cuando el Consejo que lo juzgaba lo llamó como testigo y se entabló entre ambos un debate teológico sobre las bases de su ideario, especialmente, la doctrina de la Santa Trinidad y del bautismo infantil.

En cuanto a la reivindicación de la libertad de conciencia, de «su» conciencia, son varios los momentos en los que aparecen en su obra y en su vida alusiones a la misma. Cuanto más se acerca el momento final, lógicamente, alzará su voz con más insistencia. Es 
esta llamada angustiosa y trágica la que acabará impulsando la reacción de Castellio y de otros contra Calvino, su sentencia y a favor de la libertad de conciencia.

El proceso de Ginebra brindó a un angustiado Servet la oportunidad de insistir en su tesis sobre la libertad de conciencia. El 22 de agosto de I553, cuando ya ha superado la primera fase del interrogatorio, Servet envía un escrito autógrafo al Consejo de Ginebra en el que defiende que es injusto acusarle ante la autoridad criminal por interpretar las Escrituras sin remitirle a la autoridad religiosa, pues son cuestiones que debe decidir la Iglesia, y que, aún más, no debieran tener consecuencias criminales. «Todas las cuestiones serían decididas por las iglesias y el que fuera convicto o condenado por ellas, si no quiere arrepentirse, sería excluido. Ese castigo fue siempre observado en la primera Iglesia contra los herejes...».

¡Cómo se observa que el mismo Servet teme lo peor! Que su condena no se quedará en una expulsión de las iglesias, sino que acabaría con su vida. Incluso arguye que «por haber destacado ciertos puntos de los antiguos doctores de la Iglesia, sin ningún ánimo de sedición, no debe en modo alguno estar detenido y sometido a una acusación criminal».

Este argumento volverá a ser esgrimido por Servet ya directamente contra Calvino en su escrito de 22 de septiembre de I553 cuando su final se acercaba ya. En el punto 6 del mismo vuelve a la carga preguntándole «si no sabe perfectamente que no es oficio de un ministro del Evangelio transformarse en acusador criminal, ni perseguir judicialmente a muerte a nadie». Y, con toda su osadía, contraataca acusando a Calvino de abusar, siendo ministro del Evangelio, de la criminalidad en cuestiones religiosas, de ser un «falso acusador», de «ahogar la verdad de Jesucristo» con «frívolas y calumniosas razones», y de introducir «grandes mentiras y maldades».

Servet, en resumidas cuentas, además de discutir las cuestiones teológicas que había desarrollado en sus escritos, principalmente en Restitución del Cristianismo, utiliza en su defensa un argumento olvidado prácticamente desde los primeros tiempos de la Iglesia: que los jueces civiles y criminales no pueden juzgar y condenar a los herejes. Tal será la idea y su legado que, tras su muerte, se extenderá en determinados círculos -en Basilea, en Polonia, en Holanda- y que será uno de los pilares de la reivindicación de Sebastián Castellio de su figura poco tiempo después, iniciándose así la historia de la lucha por la tolerancia y por la libertad de pensamiento y de conciencia.

Una de las páginas más brillantes de la historia de la lucha por la libertad de pensamiento y de conciencia y, en suma, por los derechos fundamentales es la reivindicación de la figura y de la obra de Miguel Servet, que se inicia justo tras su muerte. Tal fue el horror que produjo en muchas de las mentes más humanistas de la época. No se matan las ideas, sino, y eso es lo más execrable, a las personas. En este proceso de reivindicación tuvieron un papel determinante tanto teólogos reformadores como Sebastián Castellio, como intelectuales como Voltaire, el filósofo de las causas perdidas. Puede decirse que, con la Ilustración, el nombre de Miguel Servet había sido plenamente «restituido».

Así pues, la muerte de Servet no supone un olvido, ni pasar la página de la proyección de sus ideas y de su figura por mucho que su obra fuese también objeto de inquina y pasto del fuego. Tal fue el escándalo que hasta el mismo Calvino tuvo que salir en su propia defensa analizando la condena de Servet en su Defensio orthodoxae fides (I554) en la que el reformador -iparadojas de la historia!- rechaza la libertad de conciencia y justifica la condena a muerte de los herejes. 
Una de las páginas más bellas de la reivindicación de la tolerancia y de la libertad de pensamiento y de conciencia es la polémica que, a raíz de la publicación de la Defensio orthodoxae fides, va a entablar Sebastián Castellio contra Calvino que se centrará en la condena de Servet, en la persecución de los herejes y su condena a pena capital, y que, al final, convertirá al primero en un campeón de la tolerancia.

Pero el sacrificio del aragonés no fue en vano, pues supuso un punto de inflexión en los ácidos debates religiosos, en las querellas permanentes y violentas y, sobre todo, en la opinión asumida de que el «hereje» no tiene derecho a disentir, ni derecho a la vida. Lo paradójico es que las Iglesias reformadas, que surgen abanderando el derecho a opinar e interpretar los textos bíblicos de diferente manera a la Iglesia romana, reprodujesen las mismas estrategias persecutorias, y lo hiciesen contra las nuevas sectas que aparecen en el seno del movimiento protestante (anabaptistas, unitarios, socinianos). Como es bien sabido, precisamente, Servet tuvo y tiene un importante predicamento ideológico en alguna de estas corrientes.

\section{Bibliografía}

Alcalá, A, (2003), «Los dos grandes legados de Servet: el radicalismo como método intelectual y el derecho a la libertad de conciencia», Turia. Revista cultural, 63-64, pp. 22I-242.

Alcalá, A. (2006), «Nuestra deuda con Servet: inspiraciones de su doctrina para el siglo XXI» en S. Baches, coord., (2006), Miguel Servet, luz entre tinieblas, Huesca, Instituto de Estudios Sijenense, pp. 25-43.

Alcalá, A. (2006), «La sinrazón de la intolerancia en Tomás de Aquino y Juan Calvino: su rechazo por Miguel Servet, origen de la libertad de conciencia» en J. A. Escudero, coord.., Intolerancia e Inquisición, Madrid, Sociedad Estatal de Conmemoraciones Culturales, pp. 83-I07.

Betes, L. (2003), «El pensamiento teológico de Miguel Servet», Turia. Revista cultural, 63-64, pp. 255-264.

Baches, S., coord., (2006), Miguel Servet, luz entre tinieblas, Huesca, Instituto de Estudios Sijenense.

Baches, S., (2006), «Miguel Servet: apuntes sobre su vida, obra y legado» en S. Baches, coord., Miguel Servet, luz entre tinieblas, Huesca, Instituto de Estudios Sijenense, pp. 26I-278.

Bodin, J. (I985), Los seis libros de la República, selecc., trad. y estudio preliminar de P. Bravo, Madrid, Tecnos.

Castellio, S. (2009), Contra el libelo de Calvino, trad, y notas de J. Fernández Cacho, revisión de A. Gómez Rabal, Huesca, Instituto de Estudios Sijenenses Miguel Servet.

Ferrer Benimeli, J. A. (2006), «Calvino y Servet: otra forma de Inquisición» en J. A. Escudero, coord., Intolerancia e Inquisición, Madrid, Sociedad Estatal de Conmemoraciones Culturales, pp. 59-8I.

Gómez Rabal, A. (2003), «Vida de Miguel Servet» Turia. Revista cultural, 63-64, p. 209.

Hillar M. (2006), «El legado de Servet. El camino del reconocimiento de la libertad de conciencia como derecho natural y cambio de paradigma social: de Servet a Thomas Jefferson» en S, Baches, coord., Miguel Servet, luz entre tinieblas, Huesca, Instituto de Estudios Sijenense, pp. 93-Io8.

Hillar M. (2006), «La Christianismi Restitutio (Restitución del Cristianismo): el programa religioso de Miguel Servet» en S. Baches, coord., Miguel Servet, luz entre tinieblas, Huesca, Instituto de Estudios Sijenense, pp.45-68.

Locke, J. (I985), Carta sobre la Tolerancia, edic. de P. Bravo, Madrid, Tecnos.

Martínez Laínez, F. (20II), Miguel Servet. Historia de un fugitivo, Zaragoza, Institución Fernando el Católico.

Martínez de Pisón, J. (200I), Tolerancia y derechos fundamentales en las sociedades multiculturales, Madrid, Tecnos.

Saíz Valdivielso, A. C., (2002), «Fanatismo e intolerancia contra la libertad de pensar (el caso de Miguel Servet)» en Estudios jurídicos en memoria de José María Lidón, coord. por J. I. Echano Basaldúa, Universidad de Deusto, Bilbao, p. I245-I258.

Sartorelli, E. C., (2003), «Servet, pensador radical», Turia. Revista cultural, 63-64, pp. 243-254.

Servet, M. (2003), Obras completas, edición de A. Alcalá, 6 vol., Zaragoza, Prensas Universitarias.

Voltaire (I977), Tratado de la tolerancia, ed., prol. y notas de P. Togliatti, Barcelona, Grijalbo. 
Voltaire (I980), Diccionario filosófico, $2^{\text {a }}$ edic., ed. y prólogo de L. Martínez Drake, trad. de J. Areán Fernández y L. Martínez Drake, Madrid, Akal.

Zweig, S. (200I), Castellio contra Calvino. Conciencia contra violencia, trad. de B. Vías Mahou, Barcelona, Acantilado. 